ARTICLE

https://doi.org/10.1038/s41467-019-10854-1

\title{
Manganese acting as a high-performance heterogeneous electrocatalyst in carbon dioxide reduction
}

Bingxing Zhang ${ }^{1,2}$, Jianling Zhang ${ }^{1,2}$, Jinbiao Shi ${ }^{1,2}$, Dongxing Tan ${ }^{1,2}$, Lifei Liu' ${ }^{1,2}$, Fanyu Zhang ${ }^{1,2}$, Cheng Lu², Zhuizhui Su1,2, Xiuniang Tan ${ }^{1,2}$, Xiuyan Cheng ${ }^{1,2}$, Buxing Han ${ }^{1,2}$, Lirong Zheng ${ }^{3} \&$ Jing Zhang ${ }^{3}$

Developing highly efficient electrocatalysts based on cheap and earth-abundant metals for $\mathrm{CO}_{2}$ reduction is of great importance. Here we demonstrate that the electrocatalytic activity of manganese-based heterogeneous catalyst can be significantly improved through halogen and nitrogen dual-coordination to modulate the electronic structure of manganese atom. Such an electrocatalyst for $\mathrm{CO}_{2}$ reduction exhibits a maximum $\mathrm{CO}$ faradaic efficiency of $97 \%$ and high current density of $\sim 10 \mathrm{~mA} \mathrm{~cm}^{-2}$ at a low overpotential of $0.49 \mathrm{~V}$. Moreover, the turnover frequency can reach $38347 \mathrm{~h}^{-1}$ at overpotential of $0.49 \mathrm{~V}$, which is the highest among the reported heterogeneous electrocatalysts for $\mathrm{CO}_{2}$ reduction. In situ X-ray absorption experiment and density-functional theory calculation reveal the modified electronic structure of the active manganese site, on which the free energy barrier for intermediate formation is greatly reduced, thus resulting in a great improvement of $\mathrm{CO}_{2}$ reduction performance.

\footnotetext{
${ }^{1}$ Beijing National Laboratory for Molecular Sciences (BNLMS), CAS Key Laboratory of Colloid, Interface and Chemical Thermodynamics, CAS Research/ Education Center for Excellence in Molecular Sciences, Institute of Chemistry, Chinese Academy of Sciences, Beijing 100190, P. R. China. ${ }^{2}$ School of Chemical Sciences, University of Chinese Academy of Sciences, Beijing 100049, P. R. China. ${ }^{3}$ Beijing Synchrotron Radiation Facility (BSRF), Institute of High Energy Physics, Chinese Academy of Sciences, Beijing 100049, P. R. China. Correspondence and requests for materials should be addressed to J.Z. (email: zhangj|@iccas.ac.cn)
} 
E lectrochemical carbon dioxide $\left(\mathrm{CO}_{2}\right)$ reduction reaction $\left(\mathrm{CO}_{2} \mathrm{RR}\right)$ in aqueous solution is a promising approach for both decreasing atmospheric $\mathrm{CO}_{2}$ concentration and producing useful fuels ${ }^{1-3}$. How to overcome the limitations of the activation of $\mathrm{CO}_{2}$ into $\mathrm{CO}_{2}{ }^{--}$radical anion or other intermediates is the critical bottleneck ${ }^{4}$, especially at low applied overpotentials in terms of avoiding hydrogen evolution and reducing energy consumption. The heterogeneous electrocatalysts based on noble metals $\mathrm{Pd}, \mathrm{Ag}, \mathrm{Au}$ and their alloys have shown to be active for $\mathrm{CO}_{2} \mathrm{RR}$ in aqueous solution at low overpotentials ${ }^{5-11}$. It is desirable to develop efficient and selective heterogeneous electrocatalysts for $\mathrm{CO}_{2} \mathrm{RR}$ based on cheap and earth-abundant metals. Transition metal manganese $(\mathrm{Mn})$ is the third after iron and titanium among the transition elements in its natural abundance. However, the studies on Mn-based heterogeneous electrocatalysts for $\mathrm{CO}_{2} \mathrm{RR}$ have been rarely reported. Strasser and coworkers synthesized a family of metal-nitrogen-doped carbon (M-N-C) electrocatalysts including a variety of transition metals such as $\mathrm{Mn}, \mathrm{Fe}, \mathrm{Co}, \mathrm{Ni}$, and $\mathrm{Cu}$ for $\mathrm{CO}_{2}$ reduction ${ }^{12,13}$. The electrocatalytic performance of $\mathrm{Mn}-\mathrm{N}-\mathrm{C}$ remains largely limited, especially as compared with $\mathrm{Fe}-\mathrm{N}-\mathrm{C}$ and Ni-N-C catalysts $^{13-15}$. It is urgent to develop the efficient Mn-based heterogeneous electrocatalysts with high $\mathrm{CO}_{2} \mathrm{RR}$ activity and selectivity, but is challenging.

Herein, we show that the Mn-based heterogeneous catalyst can be efficient and selective electrocatalyst for converting $\mathrm{CO}_{2}$ to carbon monoxide (CO) via halogen and nitrogen dualcoordination to modulate the electronic structure of $\mathrm{Mn}$ atoms. Outstandingly, the $\mathrm{CO}$ faradaic efficiency $\left(\mathrm{FE}_{\mathrm{CO}}\right)$ is up to $97 \%$ with a current density of $\sim 10 \mathrm{~mA} \mathrm{~cm}^{-2}$ at a low overpotential of $0.49 \mathrm{~V}$. Moreover, the turnover frequency (TOF) for $\mathrm{CO}_{2} \mathrm{RR}$ can reach $38347 \mathrm{~h}^{-1}$ at overpotential of $0.49 \mathrm{~V}$, which outperforms all the reported heterogeneous electrocatalysts under similar conditions. The in situ synchrotron X-ray absorption spectra (XAS) for $\mathrm{CO}_{2} \mathrm{RR}$ and theoretical simulations reveal the promoted $\mathrm{CO}_{2}$ activation process and facilitated $\mathrm{CO}$ desorption process. This study opens up an opportunity for improving the $\mathrm{CO}_{2} \mathrm{RR}$ properties of metal electrocatalysts under mild conditions, particularly for the metals with intrinsically low activity.

\section{Results}

Synthesis and structural characterizations of $(\mathrm{Cl}, \mathrm{N})-\mathrm{Mn} / \mathrm{G}$. The Mn-based heterogeneous catalyst was synthesized by pyrolyzing a pre-formed crystalline polymer Mn-EDA-Cl (EDA = ethylenediamine) (Supplementary Figs. 1-3). The X-ray diffraction (XRD), scanning and transmission electron microscopes (SEM, TEM), and atomic force microscopy (AFM) images show the formation of graphitic carbon layer, with a lateral size of $\sim 3$ $\mu \mathrm{m}$ and thickness of $\sim 1.1 \mathrm{~nm}$ (Fig. 1a-d, Supplementary Figs. 4, $5)$. No particle decoration was observed on graphene (G) from TEM images, which is consistent with the XRD results that the diffractions from metallic Mn are absent (Supplementary Fig. 4). Energy-dispersive X-ray spectroscopy (EDS) images reveal that $\mathrm{Mn}, \mathrm{Cl}$ and $\mathrm{N}$ elements homogeneously distribute over the entire graphene (Fig. 1e). The aberration-corrected high-angle annular dark-field scanning transmission electron microscopy (HAADFSTEM) images confirm the atomically dispersed $\mathrm{Mn}$ on graphene (Fig. 1f-h). The Mn content is 0.049 wt $\%$ measured by inductively coupled plasma-optical emission spectrometer analysis (Supplementary Table 1). The as-synthesized electrocatalyst was denoted as $(\mathrm{Cl}, \mathrm{N})-\mathrm{Mn} / \mathrm{G}$.

Fine structures of $(\mathbf{C l}, \mathbf{N})-\mathbf{M n} / \mathbf{G}$. The insightful chemical and structural information of the $(\mathrm{Cl}, \mathrm{N})-\mathrm{Mn} / \mathrm{G}$ catalyst was examined by X-ray photoelectron spectra (XPS). The full XPS survey scan proves the presence of $\mathrm{Mn}, \mathrm{Cl}, \mathrm{N}$ and $\mathrm{C}$ in the catalyst (Supplementary Fig. 6). The high-resolution $\mathrm{Cl} 2 \mathrm{p}$ XPS spectrum (Fig. 2a) shows the peak at $197.7 \mathrm{eV}$ corresponding to $\mathrm{Mn}-\mathrm{Cl}$ species $^{16,17}$ and peaks at $199.6 \mathrm{eV}\left(2 \mathrm{p}_{3 / 2}\right)$ and $201.2 \mathrm{eV}\left(2 \mathrm{p}_{1 / 2}\right)$ corresponding to $\mathrm{C}-\mathrm{Cl}$ species. The $\mathrm{N} 1 \mathrm{~s}$ XPS spectrum (Fig. 2b) reveals four $\mathrm{N}$ species, including $\mathrm{Mn}-\mathrm{N}$ species at $399.2 \mathrm{eV}$, pyridinic $\mathrm{N}$ species at $398.0 \mathrm{eV}$, pyrrolic $\mathrm{N}$ species at $400.7 \mathrm{eV}$ and graphitic $\mathrm{N}$ species at $401.5 \mathrm{eV}^{13,18,19}$. The XPS results indicate that $\mathrm{Cl}$ and $\mathrm{N}$ co-coordinate with $\mathrm{Mn}$ atoms. The local structure of the catalyst at atomic level was further investigated by synchrotron XAS. For the Mn K-edge X-ray absorption near-edge structure (XANES, Fig. 2c), the (Cl, N)-Mn/G catalyst exhibits similar spectrum features to that of reference sample $\mathrm{Mn}(\mathrm{II})$ phthalocyanine $(\mathrm{Mn}(\mathrm{II}) \mathrm{Pc})$, suggesting that $(\mathrm{Cl}, \mathrm{N})-\mathrm{Mn} / \mathrm{G}$ possesses comparable $D_{4 \mathrm{~h}}$ symmetry as $\mathrm{Mn}(\mathrm{II}) \mathrm{Pc}^{20,21}$. The absorption edge position of $(\mathrm{Cl}, \mathrm{N})-\mathrm{Mn} / \mathrm{G}$ is located between those of $\mathrm{Mn}$ foil and $\mathrm{Mn}(\mathrm{II}) \mathrm{Pc}$, implying the valence of $\mathrm{Mn}$ species in $(\mathrm{Cl}, \mathrm{N})-\mathrm{Mn} / \mathrm{G}$ is less than +2 . The phase-uncorrected Fouriertransformed (FT) extended X-ray absorption fine structure (EXAFS) of $(\mathrm{Cl}, \mathrm{N})-\mathrm{Mn} / \mathrm{G}$ presents the main peak at $1.63 \AA$ (Fig. 2d), corresponding to the scattering interaction between Mn atoms and $\mathrm{Cl} / \mathrm{N}$ in the first shell of $(\mathrm{Cl}, \mathrm{N})-\mathrm{Mn} / \mathrm{G}$. Compared to the EXAFS spectrum of the reference $\mathrm{Mn}(\mathrm{II}) \mathrm{Pc}$, which shows a symmetric peak $\left(\mathrm{Mn}-\mathrm{N}_{4}\right)$ with $\mathrm{Mn}-\mathrm{N}$ scattering path at $1.49 \AA$, $(\mathrm{Cl}, \mathrm{N})-\mathrm{Mn} / \mathrm{G}$ presents an unsymmetric peak with slight migration. This can be attributed to the additional coordination of Mn$\mathrm{Cl}$ in $(\mathrm{Cl}, \mathrm{N})-\mathrm{Mn} / \mathrm{G}$ and the caused distortion of $\mathrm{Mn}$ atoms out of graphene plane. It is worth noting that the peak from $\mathrm{Mn}-\mathrm{Mn}$ scattering path $(\sim 2.3 \AA)^{22,23}$ was not observed for $(\mathrm{Cl}, \mathrm{N})-\mathrm{Mn} / \mathrm{G}$, further proving the presence of atomically dispersed $\mathrm{Mn}$. The peak at around $2.60 \AA$ can be attributed to the Mn-C scattering path in higher shells ${ }^{22-24}$. The coordination configuration of $\mathrm{Mn}$ atom for $(\mathrm{Cl}, \mathrm{N})-\mathrm{Mn} / \mathrm{G}$ was further investigated by quantitative EXAFS curve fitting analysis (Fig. 2e, f, Supplementary Fig. 7 and Table 2$)^{20,25-28}$. The best-fitting analyses clearly confirm that Mn centre is coordinated with one $\mathrm{Cl}$ atom and four $\mathrm{N}$ atoms, as illustrated in Fig. 2g. The calculated $\mathrm{Mn}-\mathrm{Cl}$ mean bond distance is $2.39 \AA$ and $\mathrm{Mn}-\mathrm{N}$ mean bond distance is $2.08 \AA$ in $(\mathrm{Cl}, \mathrm{N})-\mathrm{Mn} / \mathrm{G}$, which is longer than that in $\mathrm{Mn}(\mathrm{II}) \mathrm{Pc}(1.95 \AA)$ with the ideal square planar symmetry. The wavelet transform (WT) results give further support for the existence of $\mathrm{Mn}-\mathrm{Cl} / \mathrm{N}$ bonding (with a maximum at $\left.4.3 \AA^{-1}\right)$ in the $(\mathrm{Cl}, \mathrm{N})-\mathrm{Mn} / \mathrm{G}$ catalyst, as compared with $\mathrm{Mn}$ (II)Pc, $\mathrm{Mn}$ foil and $\mathrm{MnO}_{2}$ (Fig. 2h). Moreover, the soft XAS of N K-edge and C K-edge further confirms that the single $\mathrm{Mn}$ site bonds to $\mathrm{N}$ and excludes the existence of $\mathrm{Mn}-\mathrm{C}$ bond in $(\mathrm{Cl}, \mathrm{N})-\mathrm{Mn} / \mathrm{G}$ catalyst (Supplementary Fig. 8) ${ }^{23,29}$.

Electrochemical activities of $\mathrm{CO}_{2}$ reduction. The $\mathrm{CO}_{2}$ electrolysis of the $(\mathrm{Cl}, \mathrm{N})-\mathrm{Mn} / \mathrm{G}$ catalyst was determined by linear sweep voltammetry (LSV) in a $\mathrm{CO}_{2}$-saturated $0.5 \mathrm{M} \mathrm{KHCO}_{3}$ solution. For comparison, the $\mathrm{N}$-coordinated $\mathrm{Mn}$ single atoms supported by graphene $(\mathrm{N}-\mathrm{Mn} / \mathrm{G})$ and $\mathrm{MnO}$ nanoparticles supported by graphene $(\mathrm{MnO} / \mathrm{G})$ were also synthesized and measured (Supplementary Figs. 9-12). For (Cl, N)-Mn/G catalyst, a cathodic peak occurs at $-0.6 \mathrm{~V}$ (vs RHE) in LSV curve (Fig. 3a and Supplementary Fig. 13) and the peak current increases linearly with scan rate (Supplementary Fig. 14), which suggests that this peak originates from $\mathrm{CO}_{2}$ mass transfer controlled electrolysis process $^{20,30}$. Such a cathodic peak was not observed for the other two reference catalysts (Fig. 3a and Supplementary Fig. 13). Moreover, the $(\mathrm{Cl}, \mathrm{N})-\mathrm{Mn} / \mathrm{G}$ catalyst shows the absence of the cathodic peak and much low current density in $\mathrm{N}_{2}$-saturated $\mathrm{KHCO}_{3}$ solution (Supplementary Fig. 13), indicating that the $(\mathrm{Cl}, \mathrm{N})-\mathrm{Mn} / \mathrm{G}$ is indeed active for catalyzing $\mathrm{CO}_{2} \mathrm{RR}$. The $(\mathrm{Cl}, \mathrm{N})$ $\mathrm{Mn} / \mathrm{G}$ catalyst shows current densities of $13.4 \mathrm{~mA} \mathrm{~cm}^{-2}$ 

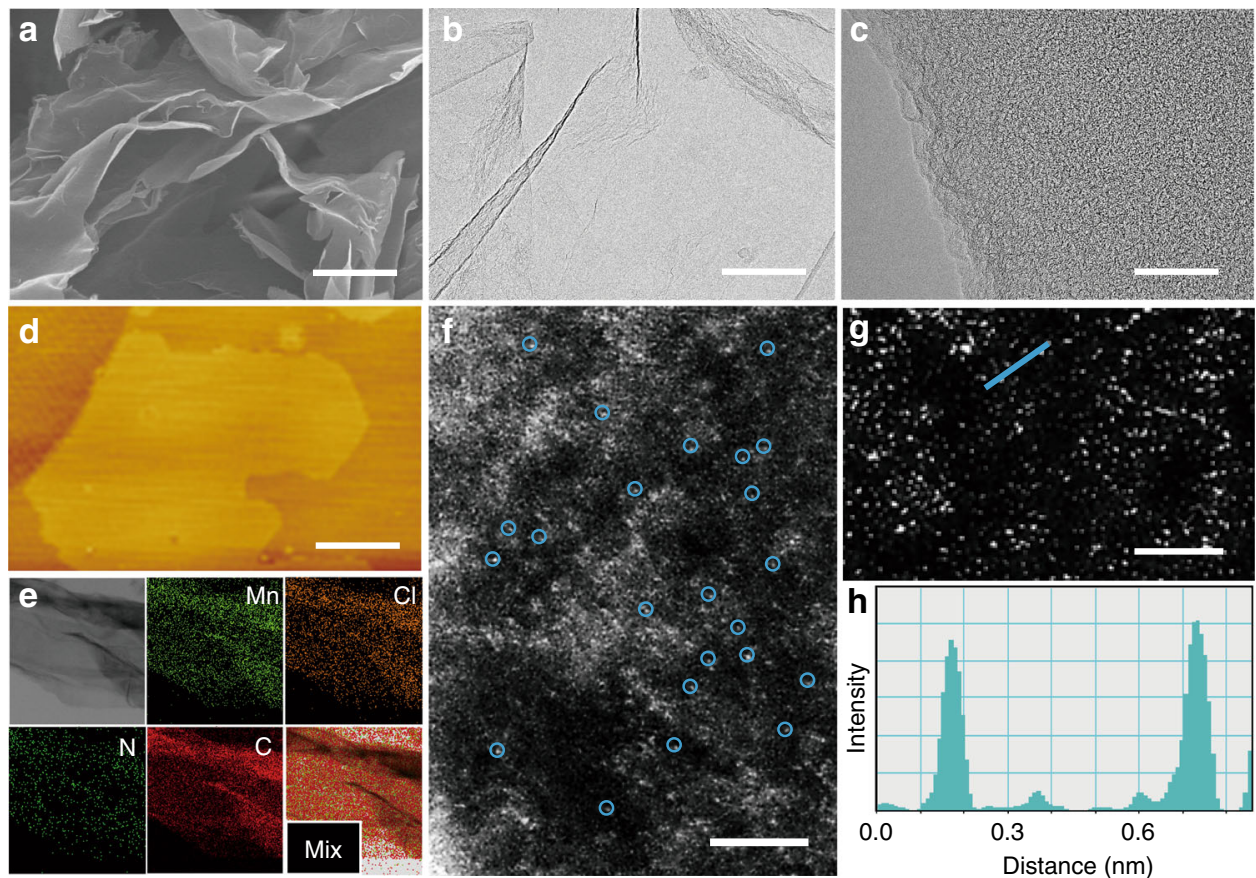

Fig. 1 Structural characterizations of (Cl, N)-Mn/G. a SEM image. b, c TEM images. d AFM image. e EDS image. f HAADF-STEM image. The high density bright dots (highlighted by blue circles) corresponding to single $\mathrm{Mn}$ atoms are homogeneously distributed across the entire carbon framework. $\mathbf{g}$ Enlarged HAADF-STEM image of Fig. 1f. h The corresponding intensity profile along the line as shown in Fig. 1g. Scale bars, $1.5 \mu \mathrm{m}$ in (a), $200 \mathrm{~nm}$ in (b), $50 \mathrm{~nm}$ in (c), $800 \mathrm{~nm}$ in (d), $2 \mathrm{~nm}$ in (f) and $1 \mathrm{~nm}$ in $(\mathbf{g})$
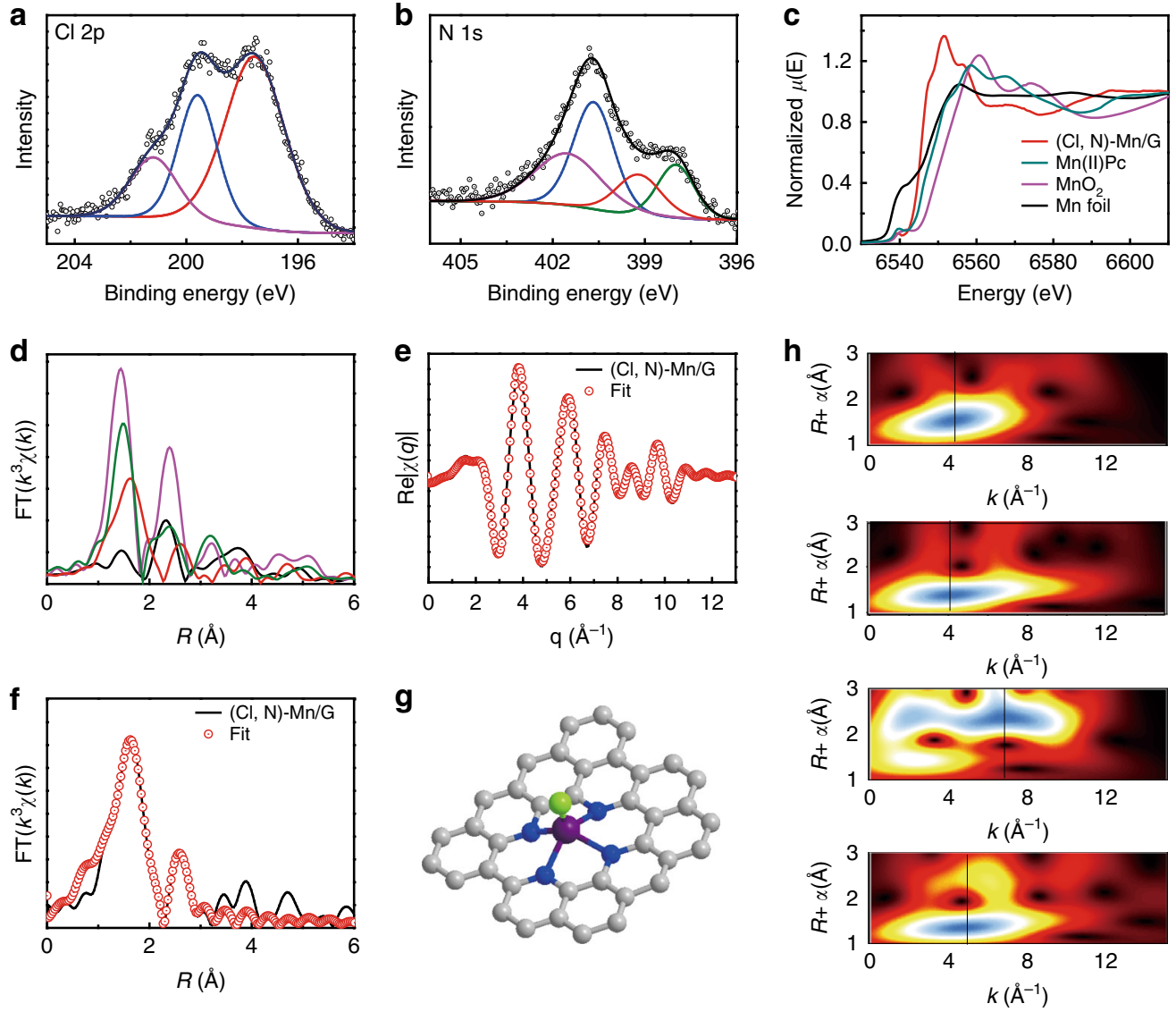

Fig. 2 Fine structure of $(\mathrm{Cl}, \mathrm{N})-\mathrm{Mn} / \mathrm{G}$. a, b High-resolution $\mathrm{Cl} 2 \mathrm{p}$ and $\mathrm{N}$ 1s XPS spectra. $\mathbf{c}$, d XANES and EXAFS spectra at Mn K-edge. (e) EXAFS fitting curves of $(\mathrm{Cl}, \mathrm{N})-\mathrm{Mn} / \mathrm{G}$ in a space. $\mathbf{f}$ EXAFS fitting curves of the $(\mathrm{Cl}, \mathrm{N})-\mathrm{Mn} / \mathrm{G}$ in $R$ space. $\mathbf{g}$ Schematic model of $(\mathrm{Cl}, \mathrm{N})-\mathrm{Mn} / \mathrm{G}: \mathrm{Mn}($ purple), $\mathrm{Cl}$ (green), $\mathrm{N}$ (blue), and $\mathrm{C}$ (gray). h WT of ( $\mathrm{Cl}, \mathrm{N})-\mathrm{Mn} / \mathrm{G}, \mathrm{Mn}(\mathrm{II}) \mathrm{Pc}, \mathrm{Mn}$ foil and $\mathrm{MnO}_{2}$ (from top to bottom) 

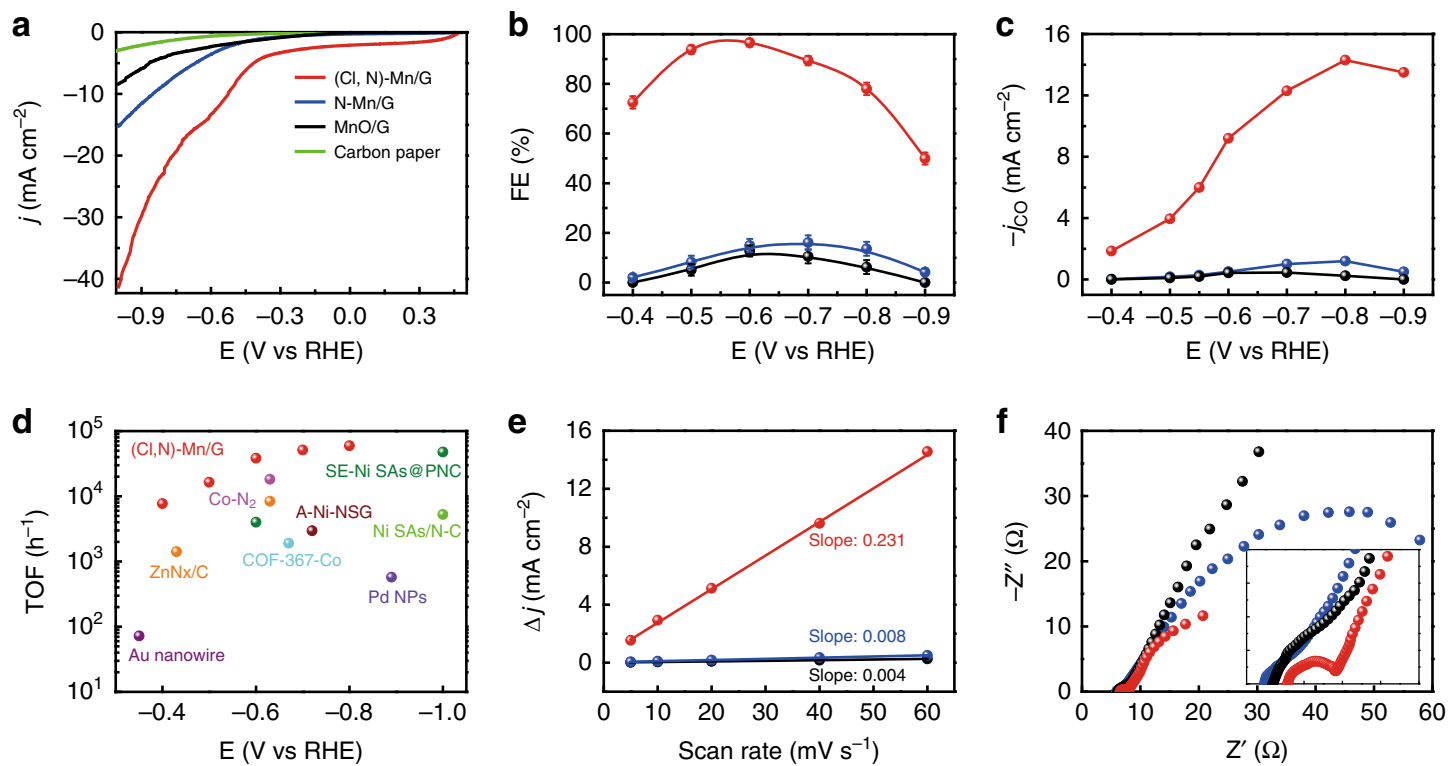

Fig. 3 Electrochemical $\mathrm{CO}_{2} \mathrm{RR}$ performance on $(\mathrm{Cl}, \mathrm{N})-\mathrm{Mn} / \mathrm{G}$ catalyst and control samples of N-Mn/G, MnO/G and carbon paper. a LSV curves of different catalysts (in a $\mathrm{CO}_{2}$-saturated $0.5 \mathrm{M} \mathrm{KHCO}_{3}$ solution, scanning rate: $10 \mathrm{mV} \mathrm{s}^{-1}$ ). b FE $\mathrm{CO}$ at various applied potentials. c Potential-dependent $\mathrm{CO}$ partial current density. d TOF of $(\mathrm{Cl}, \mathrm{N})-\mathrm{Mn} / \mathrm{G}$ catalyst compared with those of other $\mathrm{CO}_{2}$ to $\mathrm{CO}$ reduction catalysts in the Supplementary Table 57-13,29,31-41. e Charging current density differences plotted against scan rates. $\mathbf{f}$ EIS spectra. The inset shows the enlarged Nyquist plots for high frequency region. All data in $b$ are presented as mean \pm s.d.

(normalized by the geometrical surface area) at the potential of $-0.6 \mathrm{~V}$ ( $v s \mathrm{RHE}$ ), which is 3.7 -fold and 5.8 -fold relative to $\mathrm{N}-\mathrm{Mn} /$ $\mathrm{G}\left(3.6 \mathrm{~mA} \mathrm{~cm}^{-2}\right)$ and $\mathrm{MnO} / \mathrm{G}\left(2.3 \mathrm{~mA} \mathrm{~cm}^{-2}\right)$, respectively. The electrolysis test was performed in an $\mathrm{H}$-type electrochemical cell separated by a Nafion 117 membrane and the products were analyzed by ${ }^{1} \mathrm{H}$ nuclear magnetic resonance spectroscopy and gas chromatography. $\mathrm{CO}$ and $\mathrm{H}_{2}$ were the only products in the gas phase and no liquid products were detected in the potential range from -0.4 to $-0.9 \mathrm{~V}$ (vs RHE) (Supplementary Fig. 15). The $\mathrm{FE}_{\mathrm{CO}}$ reaches a maximum of $97 \%$ over $(\mathrm{Cl}, \mathrm{N})-\mathrm{Mn} / \mathrm{G}$ catalyst at $-0.6 \mathrm{~V}$ (vs RHE), which is significantly higher than that of $\mathrm{N}$ $\mathrm{Mn} / \mathrm{G}$ and $\mathrm{MnO} / \mathrm{G}(<17 \%)$ at the full potential range from -0.4 to $-0.9 \mathrm{~V}$ (vs RHE) (Fig. 3b). By using ${ }^{13} \mathrm{CO}_{2}$ as the feedstock for $\mathrm{CO}_{2} \mathrm{RR}$, it is confirmed that $\mathrm{CO}$ is the $\mathrm{CO}_{2}$ reduction product (Supplementary Fig. 16). Furthermore, the $\mathrm{CO}_{2}$ reductions catalyzed by $(\mathrm{Cl}, \mathrm{N})-\mathrm{Mn} / \mathrm{G}$ in different $\mathrm{CO}_{2}$-saturated electrolytes (0.5 $\mathrm{M} \mathrm{Na}_{2} \mathrm{SO}_{4}, \mathrm{KCl}$, and $\mathrm{K}_{2} \mathrm{SO}_{4}$ solutions) show much enhanced current densities, remarkable cathodic peaks in LSV curves and high $\mathrm{FE}_{\mathrm{CO}}$ values up to $95 \%$ (Supplementary Fig. 17), further proving that it is $\mathrm{CO}_{2}$ to be really reduced. In addition, the $\mathrm{CO}$ partial current density of $(\mathrm{Cl}, \mathrm{N})-\mathrm{Mn} / \mathrm{G}$ was plotted against the applied potential. The $(\mathrm{Cl}, \mathrm{N})-\mathrm{Mn} / \mathrm{G}$ shows a maximum value of $j_{\mathrm{CO}}=14.3 \mathrm{~mA} \mathrm{~cm}^{-2}$ at $-0.8 \mathrm{~V}$ (vs RHE), whereas those of the two reference electrocatalysts are $<1.3 \mathrm{~mA} \mathrm{~cm}^{-2}$ (Fig. 3c). Moreover, the $\mathrm{N}$ doped graphene (in absence of $\mathrm{Mn}$ ) was synthesized and tested for $\mathrm{CO}_{2} \mathrm{RR}$, which shows a very low activity $\left(1.2 \mathrm{~mA} \mathrm{~cm}^{-2}\right.$ at $-0.6 \mathrm{~V}$ (vs RHE) and FE of $9.5 \%$, Supplementary Fig. 18). It confirms that the high current density and $\mathrm{FE}_{\mathrm{CO}}$ of $(\mathrm{Cl}, \mathrm{N})-\mathrm{Mn} / \mathrm{G}$ in $\mathrm{CO}_{2} \mathrm{RR}$ originates from the coordinated $\mathrm{Mn}$ in the carbon framework. To further verify this, $\mathrm{SCN}^{-}$, a commonly adopted ion to poison metal sites, was used as an indicator for active sites 29,31 . There is a remarkable depression of catalytic activity for $(\mathrm{Cl}, \mathrm{N})-\mathrm{Mn} / \mathrm{G}$ by blocking of $\mathrm{Mn}$ atoms with $\mathrm{SCN}^{-}$, confirming the active site role of the coordinated $\mathrm{Mn}$ structure (Supplementary Fig. 19). Outstandingly, as shown in Fig. 3d, the $(\mathrm{Cl}, \mathrm{N})-\mathrm{Mn} / \mathrm{G}$ catalyst displays a high TOF value of $38347 \mathrm{~h}^{-1}$ for $\mathrm{CO}_{2} \mathrm{RR}$ at $-0.6 \mathrm{~V}$ (vs RHE), which is much higher than that of $\mathrm{N}$ -
Mn/G (744 $\mathrm{h}^{-1}$ ) (Supplementary Fig. 20) and outperforms all the reported heterogeneous electrocatalysts under similar conditions $^{7-13,29,31-41}$ (Supplementary Fig. 21 and Table 5). According to the measured double-layer capacitance, in which the slope could be a reference of electrochemical active surface area (ECSA $)^{42}$ (Fig. 3e and Supplementary Fig. 22), the ECSA for $(\mathrm{Cl}, \mathrm{N})-\mathrm{Mn} / \mathrm{G}$ is roughly 29 and 58 times higher than those of $\mathrm{N}-\mathrm{Mn} / \mathrm{G}$ and $\mathrm{MnO} / \mathrm{G}$, respectively. It suggests that the $(\mathrm{Cl}, \mathrm{N})-\mathrm{Mn} / \mathrm{G}$ catalyst can afford more accessible surface in electrolytic process, partially contributing to its enhanced activity ${ }^{42}$. The specific surface areas of $(\mathrm{Cl}, \mathrm{N})-\mathrm{Mn} / \mathrm{G}, \mathrm{N}-\mathrm{Mn} / \mathrm{G}$ and $\mathrm{MnO} / \mathrm{G}$ were determined to be 1192, 425 and $156 \mathrm{~m}^{2} \mathrm{~g}^{-1}$, respectively (Supplementary Fig. 23). The electrochemical performance gap is much higher than the specific surface area gap between the three catalysts, suggesting the enhanced inherent activity of $(\mathrm{Cl}, \mathrm{N})-\mathrm{Mn} / \mathrm{G}^{43}$. Electrochemical impedance spectroscopy (EIS) was carried out to gain further insight into $\mathrm{CO}_{2} \mathrm{RR}$ kinetics. The Nyquist plots demonstrate that $(\mathrm{Cl}, \mathrm{N})-\mathrm{Mn} / \mathrm{G}$ shows much smaller interfacial charge-transfer resistance during $\mathrm{CO}_{2}$ reduction process (Fig. 3f), suggesting a favorable faradaic process. The $\mathrm{CO}_{2}$ reduction test for $12 \mathrm{~h}$ at $-0.6 \mathrm{~V}$ (vs RHE) demonstrates the relative stability of (Cl, N)-Mn/G catalyst (Supplementary Fig. 24).

In situ XAS spectra of $(\mathrm{Cl}, \mathrm{N})-\mathrm{Mn} / \mathrm{G}$ in electrochemical $\mathrm{CO}_{2} \mathbf{R R}$. To elucidate the structure and chemical state of the active sites of $(\mathrm{Cl}, \mathrm{N})-\mathrm{Mn} / \mathrm{G}$ catalyst during $\mathrm{CO}_{2} \mathrm{RR}$, the in situ XAS spectra were recorded under operando conditions at catalytic state. The XANES shows that the Mn K-edge of as-prepared $(\mathrm{Cl}, \mathrm{N})-\mathrm{Mn} / \mathrm{G}$ is shifted to higher energy after immersing in $\mathrm{CO}_{2}$ saturated $0.5 \mathrm{M} \mathrm{KHCO}_{3}$ (Fig. 4a), which can be attributed to the increased oxidation of the $\mathrm{Mn}$ sites due to the charge transfer from low-valence $\mathrm{Mn}$ to the carbon $2 \mathrm{p}$ orbital in $\mathrm{CO}_{2}$ to form a $\mathrm{CO}_{2}{ }^{\delta-}$ species ${ }^{44,45}$. During electrochemical $\mathrm{CO}_{2}$ reduction at $-0.6 \mathrm{~V}$ (vs RHE), the Mn K-edge shifts back to lower energy that is even lower than that of the original $(\mathrm{Cl}, \mathrm{N})-\mathrm{Mn} / \mathrm{G}$ catalyst. It indicates the ongoing $\mathrm{CO}_{2}$ reduction and high activation ability of 

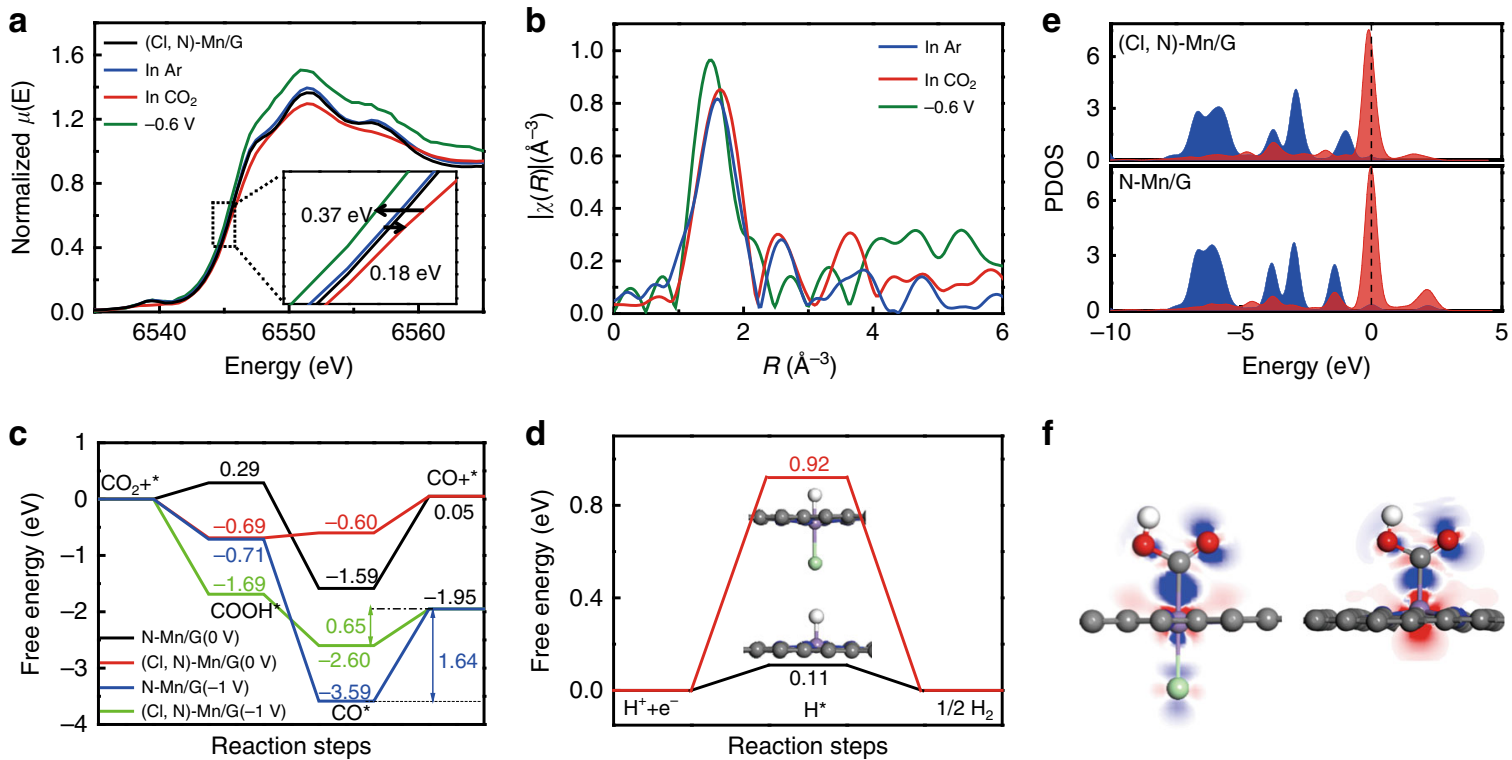

f
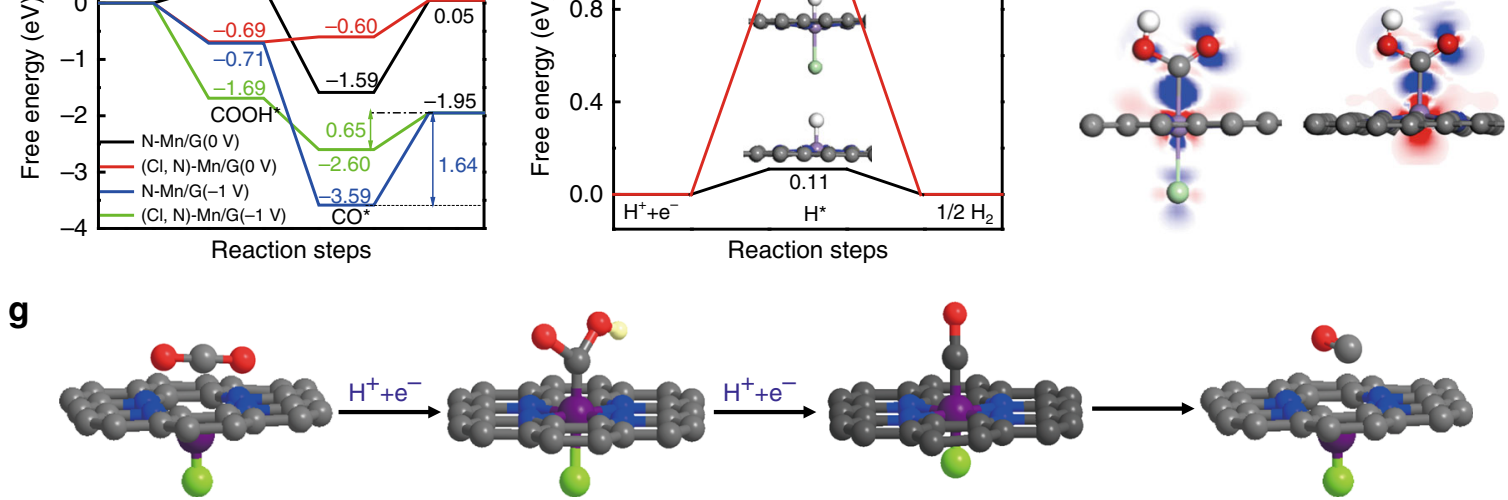

Fig. 4 In situ XAS experiment and DFT calculation. a Normalized XANES of (Cl, N)-Mn/G catalyst under various conditions (inset is the magnified image). b Fourier transform magnitudes of EXAFS spectra of $(\mathrm{Cl}, \mathrm{N})-\mathrm{Mn} / \mathrm{G}$. c Calculated free energy of $\mathrm{CO}_{2} \mathrm{RR}$. $\mathbf{d}$ Calculated free energy of hydrogen adsorption. e Projected density of states (PDOS) of the $\mathrm{COOH}^{\star} 2 \mathrm{p}$ state (blue-shaded areas) and d-projected DOS of $\mathrm{Mn}$ (red-shaded areas) in the adsorption structures for (Cl, N)-Mn/G and N-Mn/G, respectively. f Electron density difference for $\mathrm{COOH}^{\star}$ adsorbed on (Cl, N)-Mn/G (left) and N-Mn/G (right). The blue and red denote the electron accumulation and electron depletion, respectively. $\mathbf{g}$ Structural evolution of the active site for (Cl, N)- $\mathrm{Mn} / \mathrm{G}$ in electrochemical $\mathrm{CO}_{2} \mathrm{RR}$ (Mn: purple, $\mathrm{Cl}$ : green, $\mathrm{N}$ : blue, $\mathrm{O}$ : red, $\mathrm{H}$ : white and $\mathrm{C}$ : gray)

Mn center for $\mathrm{CO}_{2}{ }^{45}$. However, the in situ Mn K-edge XANES spectra of $\mathrm{N}-\mathrm{Mn} / \mathrm{G}$ show little changes under similar operating conditions (Supplementary Fig. 25), suggesting the important role of $\mathrm{Cl}$ coordination to the oxidation states of $\mathrm{Mn}$ in $\mathrm{CO}_{2} \mathrm{RR}$ process. Fourier transform of the EXAFS shows that the intensity of the main peak at approximately $1.62 \AA$ slightly increases (Fig. 4b), which can be ascribed to the additional Mn-C bond ${ }^{46}$ from the $\mathrm{CO}_{2}$ interacted with $\mathrm{Mn}$ center. The main peak is shifted to lower length $(\sim 0.14 \AA)$ and the $\mathrm{Mn}-\mathrm{Cl}$ bond is enlarged during $\mathrm{CO}_{2}$ reduction at $-0.6 \mathrm{~V}$ (vs RHE), which suggests the recovery of distortion of $\mathrm{Mn}$ atoms to form a stable plane structure due to the additional $\mathrm{Cl}$ interaction ${ }^{47}$.

Density functional theory (DFT) calculations and electrochemical $\mathrm{CO}_{2} \mathrm{RR}$ mechanism. DFT calculations were performed to further understand the intrinsic property and reactivity of $(\mathrm{Cl}$, $\mathrm{N})-\mathrm{Mn} / \mathrm{G}$ catalyst. The formation of adsorbed intermediate $\mathrm{COOH}^{\star}$ was investigated for the potential limiting step, which is the initial reduction barrier for $\mathrm{CO}_{2}$-to- $\mathrm{CO}$ reduction ${ }^{10,11,48 \text {, The }}$ optimized configurations of $(\mathrm{Cl}, \mathrm{N})-\mathrm{Mn} / \mathrm{G}$ show the distortion of Mn atoms out of graphene plane (Supplementary Fig. 26a), which would promote the adsorption of $\mathrm{CO}_{2}$ and $\mathrm{COOH}^{*}$ intermediates on catalyst surface ${ }^{49}$ (Supplementary Fig. 27). After interacting with $\mathrm{COOH}^{*}$ intermediates (Supplementary Fig. 26b and Table 4$)$, the $(\mathrm{Cl}, \mathrm{N})-\mathrm{Mn} / \mathrm{G}$ presents a recovered in-plane structure of $\mathrm{Mn}$ atom and the $\mathrm{Mn}-\mathrm{Cl}$ bond length (2.31 $\mathrm{A}$ ) is longer than that of the original $(\mathrm{Cl}, \mathrm{N})-\mathrm{Mn} / \mathrm{G}(2.17 \AA)$, which is in accord with the in situ XAS experiment results. By contrast, $\mathrm{N}-\mathrm{Mn} / \mathrm{G}$ shows a distorted structure of Mn center after adsorbing intermediate $\mathrm{COOH}^{\star}$, presenting lower adsorption energy $\left(\Delta E_{\text {ads }}\right.$ $=-1.62 \mathrm{eV})$ than that of $(\mathrm{Cl}, \mathrm{N})-\mathrm{Mn} / \mathrm{G}\left(\Delta E_{\mathrm{ads}}=-2.36 \mathrm{eV}\right)$ (Supplementary Fig. 26c, d and Table 3). The free energy profiles of $\mathrm{CO}_{2} \mathrm{RR}$ catalyzed by $(\mathrm{Cl}, \mathrm{N})-\mathrm{Mn} / \mathrm{G}$ and $\mathrm{N}-\mathrm{Mn} / \mathrm{G}$ are shown in Fig. 4c and Supplementary Fig. 28. Compared with N-Mn/G, there are an improvement of $\Delta \mathrm{G}$ for the first step $(0.98 \mathrm{eV})$ and a decrease of CO desorption free energy $(0.99 \mathrm{eV})$ for $(\mathrm{Cl}, \mathrm{N})-\mathrm{Mn} / \mathrm{G}$. As a result, the $\mathrm{CO}_{2} \mathrm{RR}$ on $(\mathrm{Cl}, \mathrm{N})-\mathrm{Mn} / \mathrm{G}$ is much more effective than that on $\mathrm{N}-\mathrm{Mn} / \mathrm{G}$. At the potential of $U=-1.0 \mathrm{~V}$ vs RHE, the negative potential further favors the formation of $\mathrm{COOH}^{*}$. $\mathrm{CO}$ release process can also be optimized on $(\mathrm{Cl}, \mathrm{N})-\mathrm{Mn} / \mathrm{G}$, according to the much lower energy for $\mathrm{CO}^{*}$ desorption $(0.65 \mathrm{eV})$ than that of N-Mn/G $(1.64 \mathrm{eV})$. Moreover, the free energy profiles of hydrogen adsorption on the two catalysts were calculated. The $(\mathrm{Cl}, \mathrm{N})-\mathrm{Mn} / \mathrm{G}$ shows much higher formation energy for $\mathrm{H}^{\star}$ adsorption $(0.92 \mathrm{eV})$ than that of $\mathrm{N}-\mathrm{Mn} / \mathrm{G}(0.11 \mathrm{eV})$, proving that the $\mathrm{H}_{2}$ evolution reaction is well inhibited on $(\mathrm{Cl}, \mathrm{N})-\mathrm{Mn} / \mathrm{G}$ (Fig. 4d and Supplementary Fig. 29).

The electronic structures of the Mn atoms with different ligand conditions were further calculated. The position of d-band center $\left(E_{\mathrm{dbc}}\right)$ for $(\mathrm{Cl}, \mathrm{N})-\mathrm{Mn} / \mathrm{G}$ shows a downshift of $0.38 \mathrm{eV}$ after interacting with $\mathrm{COOH}^{\star}$ (Fig. 4e, Supplementary Fig. 30 and Table 4), which is much larger than that in $\mathrm{N}-\mathrm{Mn} / \mathrm{G}(0.12 \mathrm{eV})$. It suggests more electrons transferred between $\mathrm{COOH}^{\star}$ and $(\mathrm{Cl}, \mathrm{N})$ $\mathrm{Mn} / \mathrm{G}$ owing to the contribution of $\mathrm{Cl}$ coordination (Supplementary Fig. 31$)^{20,50}$. Accordingly, the $\mathrm{COOH}^{\star}$ on $(\mathrm{Cl}, \mathrm{N})-\mathrm{Mn} / \mathrm{G}$ shows wider PDOS than that on $\mathrm{N}-\mathrm{Mn} / \mathrm{G}$ due to the more gain electrons on the former. The additional electrons transfered between $\mathrm{Mn}$ and $\mathrm{Cl}$ in $(\mathrm{Cl}, \mathrm{N})-\mathrm{Mn} / \mathrm{G}$ can also be observed in 
Fig. 4f. Similarly, there exists significant electron transfer in $\mathrm{Mn}-\mathrm{C}$ bonding area between $\mathrm{COOH}^{\star}$ and $(\mathrm{Cl}, \mathrm{N})-\mathrm{Mn} / \mathrm{G}$, suggesting a strong interaction between these two parts. Based on above analyses, the structural evolution of the active site during electrochemical $\mathrm{CO}_{2} \mathrm{RR}$ is proposed (Fig. $4 \mathrm{~g}$ ). The $\mathrm{Cl}$ coordination induces distorted single-atom $\mathrm{Mn}$ center to facilitate the adsorption of $\mathrm{CO}_{2}$ and $\mathrm{COOH}^{*}$, and then stabilizes a low-energy transition state as well as facilitates the final CO desorption process. These processes are in favor of reducing the energy barrier of intermediate formation for electrochemical $\mathrm{CO}_{2} \mathrm{RR}$.

\section{Discussion}

The above results prove that the electronic state of the single $\mathrm{Mn}$ active center could be tuned by changing its adjacent chemical environment during electrochemical process through $\mathrm{Cl}$ and $\mathrm{N}$ dual-coordination. The performing principle for highperformance electrocatalytic $\mathrm{CO}_{2} \mathrm{RR}$ was expanded to other systems. First, the (Br, N)-Mn/G and (I, N)-Mn/G catalysts were synthesized by the similar route for synthesizing $(\mathrm{Cl}, \mathrm{N})-\mathrm{Mn} / \mathrm{G}$ catalyst, which exhibit excellent activities and selectivities for electrocatalytic $\mathrm{CO}_{2} \mathrm{RR}$ (Supplementary Figs. 32-35). For example, $(\mathrm{Br}, \mathrm{N})-\mathrm{Mn} / \mathrm{G}$ and (I, N)-Mn/G catalysts respectively show $\mathrm{FE}_{\mathrm{CO}}$ of $92 \%$ at $-0.6 \mathrm{~V}$ (vs RHE) and $89 \%$ at $-0.5 \mathrm{~V}$ (vs RHE), which is 6.4-fold and 10.4-fold $\mathrm{FE}_{\mathrm{CO}}$ of halogen-free $\mathrm{N}-\mathrm{Mn} / \mathrm{G}$, respectively (Supplementary Fig. 36). Second, the (Cl, N)-Fe/G and $(\mathrm{Cl}, \mathrm{N})-\mathrm{Co} / \mathrm{G}$ were synthesized and both of them exhibit much enhanced performance for electrocatalytic $\mathrm{CO}_{2} \mathrm{RR}$ compared to their counterparts without $\mathrm{Cl}$ coordination (Supplementary Figs. 37 and 38). The electrocatalytic activities of $(\mathrm{Cl}$, $\mathrm{N})-\mathrm{Fe} / \mathrm{G}$ and $(\mathrm{Cl}, \mathrm{N})-\mathrm{Co} / \mathrm{G}$ are lower than that of $(\mathrm{Cl}, \mathrm{N})-\mathrm{Mn} / \mathrm{G}$. In other words, the positive effect of $\mathrm{Cl}$ is more dramatic when the metal is $\mathrm{Mn}$ as compared with the effect for $\mathrm{Co}$ and $\mathrm{Fe}$, indicating that the performance of $(\mathrm{Cl}, \mathrm{N})-\mathrm{M} / \mathrm{G}$ catalyst has a strong dependence on the nature of transition metal.

In summary, we demonstrate that the electrocatalytic activity of Mn-based heterogeneous catalyst can be significantly improved through halogen and nitrogen dual-coordination to modulate the electronic structure of $\mathrm{Mn}$ atom. The maximum $\mathrm{FE}_{\mathrm{CO}}$ can reach $97 \%$ with a high current density of $\sim 10 \mathrm{~mA} \mathrm{~cm}^{-2}$ at a low overpotential of $0.49 \mathrm{~V}$. Moreover, the TOF value for $\mathrm{CO}_{2} \mathrm{RR}$ is up to $38347 \mathrm{~h}^{-1}$ at overpotential of $0.49 \mathrm{~V}$, which outperforms all the reported heterogeneous electrocatalysts including noble metal catalysts. The superior catalytic performance originates from the modified electronic structure of the active Mn site, on which the free energy barrier for rate-limiting step of the intermediate formation is greatly reduced. This work provides a promising method for improving the $\mathrm{CO}_{2} \mathrm{RR}$ properties of metal electrocatalysts under mild conditions, especially for the metals with intrinsically low activity. We anticipate that the highly efficient and low-cost Mn-based heterogeneous catalyst may find more applications in other electrochemical reactions.

\section{Methods \\ Materials. Anhydrous manganese chloride (99.99\%), cobalt nitrate hexahydrate (>99\%), cobalt chloride hexahydrate $(99.9 \%)$, potassium bicarbonate $(99 \%)$, hydrochloric acid (grade), ethanol (A. R. grade) and urea (99\%) were provided by Sinopharm Chemical Reagent Co., Ltd. Manganese bromide hydrate (98\%), man- ganese nitrate tetrahydrate $(>98 \%)$, Iron chloride $(99 \%)$, Iron nitrate nonahydrate (99\%), ethylenediamine (EDA) $(99.5 \%)$, potassium iodide (99\%), citric acid (99.5\%), Nafion D-521 dispersion (5\% w/w in water and 1-propanol, $\geq 0.92 \mathrm{meg} / \mathrm{g}$ exchange capacity), Nafion N-117 membrane $(0.180 \mathrm{~mm}$ thick, $\geq 0.90 \mathrm{meg} / \mathrm{g}$ exchange capa- city) and Toray Carbon Paper (CP, TGP-H-60, $19 \times 19 \mathrm{~cm})$ were purchased from Alfa Aesar China Co., Ltd. $\mathrm{CO}_{2}(>99.999 \%)$ was provided by Beijing Analysis Instrument Factory.}

Synthesis of (Cl, N)-Mn/G and $\mathbf{N}-\mathbf{M n} / \mathbf{G}$. Typically, anhydrous manganese chloride $(1.0 \mathrm{~g})$ was dissolved in $30 \mathrm{~mL}$ of ethanol. Then $1 \mathrm{~mL}$ ethylenediamine was added to the above solution under vigorous stirring for $10 \mathrm{~h}$ at room temperature.
After the reaction, the product was separated by centrifugation and washed with ethanol, and finally dried overnight at $60^{\circ} \mathrm{C}$. The obtained precursor was annealed at $900{ }^{\circ} \mathrm{C}$ for $1 \mathrm{~h}$ in nitrogen atmosphere with a ramping rate of $3{ }^{\circ} \mathrm{C} \mathrm{min}^{-1}$. After cooling down to room temperature, the $(\mathrm{Cl}, \mathrm{N})-\mathrm{Mn} / \mathrm{G}$ was obtained by leaching the calcined product with $\mathrm{HCl}$ to remove the free standing metallic residues. The $\mathrm{N}-\mathrm{Mn} / \mathrm{G}$ was obtained under the same procedure except that the manganese chloride was replaced by manganous nitrate

Synthesis of MnO/G and N-G. In a typical synthesis, urea (3.0 g), citric acid $(1.0 \mathrm{~g})$ and manganous nitrate $(0.5 \mathrm{~g})$ were dispersed in deionized water $(5 \mathrm{~mL})$ under continuous stirring for $0.5 \mathrm{~h}$ and then dried at $80^{\circ} \mathrm{C}$. The obtained solid was annealed at $900{ }^{\circ} \mathrm{C}$ for $1 \mathrm{~h}$ at a heating rate of $3{ }^{\circ} \mathrm{C} \mathrm{min}-1$ under nitrogen flow. After cooling down to room temperature, the final powder sample was collected. The N-G sample was synthesized by a route similar to that for $\mathrm{MnO} / \mathrm{G}$ preparation, involving no manganous nitrate.

Synthesis of (Br, N)-Mn/G and (I, N)-Mn/G. For the synthesis of (Br, N)-Mn/G, manganese bromide hydrate $(2.27 \mathrm{~g})$ was firstly dissolved in $30 \mathrm{~mL}$ of ethanol. Then $1 \mathrm{~mL}$ ethylenediamine was added to the above solution under vigorous stirring for $10 \mathrm{~h}$ at room temperature. After reaction, the product was separated by centrifugation and washed with ethanol, and finally dried overnight at $60^{\circ} \mathrm{C}$. The obtained precursor was annealed and processed under same procedure for $(\mathrm{Cl}, \mathrm{N})$ $\mathrm{Mn} / \mathrm{G}$ synthesis to obtain the ( $\mathrm{Br}, \mathrm{N})-\mathrm{Mn} / \mathrm{G}$. The (I, N)-Mn/G was synthesized under the same procedure except that manganese bromide was replaced by manganese nitrate tetrahydrate $(2.0 \mathrm{~g})$ and potassium iodide $(1.0 \mathrm{~g})$.

Synthesis of (Cl, N)-Fe/G and N-Fe/G. $(\mathrm{Cl}, \mathrm{N})-\mathrm{Fe} / \mathrm{G}$ and N-Fe/G were obtained by the route for synthesizing $(\mathrm{Cl}, \mathrm{N})-\mathrm{Mn} / \mathrm{G}$ and $\mathrm{N}-\mathrm{Mn} / \mathrm{G}$ under the same procedure except that manganese salt was replaced by cobalt chloride and cobalt nitrate, respectively.

Synthesis of $(\mathbf{C l}, \mathbf{N})-\mathbf{C o} / \mathbf{G}$ and $\mathbf{N}-\mathbf{C o} / \mathbf{G} .(\mathrm{Cl}, \mathrm{N})-\mathrm{Co} / \mathrm{G}$ and $\mathrm{N}-\mathrm{Co} / \mathrm{G}$ were obtained by the route for synthesizing $(\mathrm{Cl}, \mathrm{N})-\mathrm{Mn} / \mathrm{G}$ and $\mathrm{N}-\mathrm{Mn} / \mathrm{G}$ under the same procedure except that manganese salt was replaced by cobalt chloride and cobalt nitrate, respectively.

Characterizations. Powder X-ray diffraction pattern was performed on a Rigaku $\mathrm{D} / \mathrm{max}-2500$ diffractometer with $\mathrm{Cu} \mathrm{Ka}$ radiation $(\lambda=1.5418 \AA)$ at $40 \mathrm{kV}$ and $200 \mathrm{~mA}$. The morphologies were characterized by SEM (HITACHI S-4800), TEM (JEOL-1010) operated at $100 \mathrm{kV}$ and HRTEM (JEOL-2100F) operated at $200 \mathrm{kV}$. The high-angle annular dark-field scanning transmission electron microscopy (HAADF-STEM) characterization was performed on a JEOL JEM-ARF200F TEM/ STEM with a spherical aberration corrector. AFM measurement was performed on a tapping-mode atomic force microscope (Nanoscope IIIa, Digital Instruments, Santa Barbara, CA), with a silicon cantilever probes. XPS was determined by VG Scientific ESCALab220i-XL spectrometer using Al Ka radiation. The $500 \mu \mathrm{m}$ X-ray spot was used. The base pressure in the analysis chamber was about $3 \times 10^{-10} \mathrm{mbar}$ The element contents of Mn were determined by ICP-AES (VISTA-MPX). The elemental contents of $\mathrm{C}, \mathrm{Cl}$ and $\mathrm{N}$ were determined using Flash EA1112 from Thermo. Data of XAFS were processed using the Athena and Artemis programs of thee IFEFFIT package based on FEFF 6. Prior to merging, the spectra were aligned to the first and largest peak in the smoothed first derivative of the absorption spectrum, background removed, and normalized. Data were processed with $k^{2}$ weighting and an Rbkg value of 1.0. Merged data sets were aligned to the largest peak in the first derivative of the adsorption spectrum. Normalized $\mu(E)$ data were obtained directly from the Athena program of the IFEFFIT package. The quantitative structural parameters were obtained via a least-squares curve parameter fitting method using ARTEMIS module.

Electrochemical test. The catalysts $(1.0 \mathrm{mg})$ and $10 \mu \mathrm{L}$ of a $5 \mathrm{wt} \%$ Nafion solution were ultrasonically mixed with $100 \mu \mathrm{L}$ of ethanol to form inks. A loading of $0.5 \mathrm{mg} \mathrm{cm}-2$ was obtained on the surface of the $\mathrm{CP}$ electrode by dropping the catalyst ink. Electrocatalytic $\mathrm{CO}_{2} \mathrm{RR}$ was evaluated in a $\mathrm{H}$-type electrochemical cell with three electrode system in $\mathrm{CO}_{2}$-saturated $0.5 \mathrm{M} \mathrm{KHCO}_{3}$ electrolyte. A Pt gauze and an $\mathrm{Ag} / \mathrm{AgCl}(3.5 \mathrm{M} \mathrm{KCl})$ were used as the counter electrode and reference electrode, respectively. The working and reference electrodes were placed in the cathode chamber, while the counter electrode was placed in the anode chamber, which was separated by a piece of Nafion 117 ionic exchange membrane to avoid the re-oxidation of $\mathrm{CO}_{2} \mathrm{RR}$-generated products. The electrolyte was bubbled with $\mathrm{N}_{2}$ or $\mathrm{CO}_{2}$ for at least $30 \mathrm{~min}$ to form $\mathrm{N}_{2}$ or $\mathrm{CO}_{2}$ saturated solution and maintained this flow rate during measurements. LSV test was performed in $\mathrm{CO}_{2}$-saturated $0.5 \mathrm{M}$ $\mathrm{KHCO}_{3}$ solution with a scan rate of $10 \mathrm{mV} / \mathrm{s}$. ECSA referred the $\mathrm{CV}$ results under the potential windows of $0.23 \mathrm{~V} \sim 0.13 \mathrm{~V}$ (vs RHE). EIS measurements were carried out by applying at $-0.5 \mathrm{~V}$ (vs RHE) with $5 \mathrm{mV}$ amplitude in a frequency range from $100 \mathrm{KHz}$ to $100 \mathrm{mHz}$. For the faradaic efficiency analysis, gas products were detected by gas chromatograph (GC, HP 4890D), which was equipped with FID and TCD detectors using helium as the internal standard. The liquid product was analyzed by ${ }^{1} \mathrm{H}$ NMR on Bruker AVANCE AV III 400. The isotope-labeled 
experiment was performed using ${ }^{13} \mathrm{CO}_{2}$ and the gas products were analyzed using gas chromatography-mass spectrometry (GC-MS, 7890A and 5975C, Agilent).

Evaluation of TOF. The TOF for $\mathrm{CO}$ was calculated as follows:

$$
\operatorname{TOF}\left(\mathrm{h}^{-1}\right)=\frac{j_{\mathrm{co}} /(N F)}{m_{\mathrm{cat}} \times \omega / M_{\mathrm{Mn}}} \times 3600
$$

$j_{\mathrm{CO}}$ : partial current $(\mathrm{A})$ for $\mathrm{CO}$ product;

$N$ : the number of electron transferred for product formation, which is 2 for CO; $F$ : faradaic constant, $96485 \mathrm{C} \mathrm{mol}^{-1}$;

$m_{\text {cat }}:$ catalyst mass in the electrode, g;

$\omega$ : Mn loading in the catalyst;

$M_{\mathrm{Mn}}$ : atomic mass of $\mathrm{Mn}, 54.94 \mathrm{~g} \mathrm{~mol}^{-1}$

In situ X-ray absorption spectroscopy. The XAFS experiment was carried out at Beamline 1W1B at BSRF. A home-made plastic electrochemical cell was employed for in situ XAS measurement under the sensitive fluorescence model. The cell was filled with electrolyte $\left(0.5 \mathrm{M}\right.$ aqueous $\left.\mathrm{KHCO}_{3}\right) . \mathrm{Ag} / \mathrm{AgCl}$ and $\mathrm{Pt}$ gauze were used as reference electrode and counter electrode, respectively. The working electrode compartment had walls with a single circular hole of $1.0 \mathrm{~cm}$ in diameter. A catalyst/ thin carbon paper as the working electrode was in contact with a slip of copper tape and fixed with Kapton (polyimide) tape to the exterior of the wall of the cell, over the $1.0 \mathrm{~cm}$ hole, catalyst layer facing inwards. During the measurement, a series of potentials were applied to the working electrode.

Computational details for calculations. The first principles calculations in the framework of DFT, including structural, electronic performances, were carried out based on the Cambridge Sequential Total Energy Package known as CASTEP. The exchange-correlation functional under the generalized gradient approximation (GGA) with norm-conserving pseudopotentials and Perdew-Burke-Ernzerhof functional was adopted to describe the electron-electron interaction. An energy cutoff of $750 \mathrm{eV}$ was used and a k-point sampling set of $5 \times 5 \times 1$ was tested to be converged. A force tolerance of $0.01 \mathrm{eV} \AA^{-1}$, energy tolerance of $5.0 \times 10^{-7} \mathrm{eV}$ per atom and maximum displacement of $5.0 \times 10^{-4} \AA$ were considered. Each atom in the storage models was allowed to relax to the minimum in the enthalpy without any constraints. The vacuum space along the $\mathrm{z}$ direction was set to be $15 \AA$, which was enough to avoid the interaction between the two neighboring images. The $\mathrm{COOH}, \mathrm{H}$, or $\mathrm{CO}$ group was adsorbed on the surface of $\mathrm{N}-\mathrm{Mn} / \mathrm{G}$ and $(\mathrm{Cl}, \mathrm{N})-\mathrm{Mn} / \mathrm{G}$, respectively.

The adsorption energy $\Delta E_{\text {ads }}$ was defined as:

$$
\Delta E_{\text {ads }}=E_{\text {after }}-E_{\text {before }}+E_{A}
$$

where $E_{\text {before }}$ and $E_{\text {after }}$ denote the total energy of substrates before and after adsorbing A group ( $\mathrm{COOH}, \mathrm{CO}$, or $\mathrm{H}), E_{A}$ is the energy of A group.

$$
\Delta G=\Delta E_{\mathrm{ads}}+\Delta E_{\mathrm{ZPE}}-T \Delta S
$$

where $\Delta E$ denotes the adsorption energy, $\Delta E_{\mathrm{ZPE}}$ and $\Delta S$ are the changes of zeropoint energy and entropy, and the temperature $T$ is $300 \mathrm{~K}$.

Reporting summary. Further information on research design is available in the Nature Research Reporting Summary linked to this article.

\section{Data availability}

The data supporting the findings of this study are available within the article and its Supplementary information files. All data is available from the authors upon reasonable request.

\section{Code availability}

All code supporting the findings of this study are available from the corresponding author on request.

Received: 26 November 2018 Accepted: 17 May 2019

Published online: 05 July 2019

\section{References}

1. Turner, J. A. A realizable renewable energy future. Science 285, 687-689 (1999).

2. Rosen, B. A. et al. Ionic liquid-mediated selective conversion of $\mathrm{CO}_{2}$ to $\mathrm{CO}$ at low overpotentials. Science 334, 643-644 (2011).

3. Qiao, J. L., Liu, Y. Y., Hong, F. \& Zhang, J. J. A review of catalysts for the electroreduction of carbon dioxide to produce low-carbon fuels. Chem. Soc. Rev. 43, 631-675 (2014).
4. Gao, S. et al. Partially oxidized atomic cobalt layers for carbon dioxide electroreduction to liquid fuel. Nature 529, 68-71 (2016).

5. Liu, M. et al. Enhanced electrocatalytic $\mathrm{CO}_{2}$ reduction via field-induced reagent concentration. Nature 537, 382-386 (2016).

6. Rogers, C. et al. Synergistic enhancement of electrocatalytic $\mathrm{CO}_{2}$ reduction with gold nanoparticles embedded in functional graphene nanoribbon composite electrodes. J. Am. Chem. Soc. 139, 4052-4061 (2017).

7. Lu, Q. et al. A selective and efficient electrocatalyst for carbon dioxide reduction. Nat. Commun. 5, 3242 (2014).

8. Kim, C. et al. Achieving selective and efficient electrocatalytic activity for $\mathrm{CO}_{2}$ reduction using immobilized silver nanoparticles. J. Am. Chem. Soc. 137, 13844-13850 (2015)

9. Ma, M., Trzesniewski, B. J., Xie, J. \& Smith, W. A. Selective and efficient reduction of carbon dioxide to carbon monoxide on oxide-derived nanostructured silver electrocatalysts. Angew. Chem., Int. Ed. 55, 9748-9752 (2016).

10. Gao, D. F. et al. Size-Dependent electrocatalytic reduction of $\mathrm{CO}_{2}$ over $\mathrm{Pd}$ nanoparticles. J. Am. Chem. Soc. 137, 4288-4291 (2015).

11. Zhu, W. et al. Active and selective conversion of $\mathrm{CO}_{2}$ to $\mathrm{CO}$ on ultrathin $\mathrm{Au}$ nanowires. J. Am. Chem. Soc. 136, 16132-16135 (2014)

12. Varela, A. S. et al. Metal-doped nitrogenated carbon as an efficient catalyst for direct $\mathrm{CO}_{2}$ electroreduction to $\mathrm{CO}$ and hydrocarbons. Angew. Chem. Int. Ed. 54, 10758-10762 (2015)

13. Ju, W. et al. Understanding activity and selectivity of metal-nitrogen-doped carbon catalysts for electrochemical reduction of $\mathrm{CO}_{2}$. Nat. Commun. 8, 944 (2017).

14. Pan, F. P., Deng, W., Justiniano, C. \& Li, Y. Identification of champion transition metals centers in metal and nitrogencodoped carbon catalysts for $\mathrm{CO}_{2}$ reduction. Appl. Catal. B: Environ. 226, 463-472 (2018).

15. Moller, T. et al. Efficient $\mathrm{CO}_{2}$ to $\mathrm{CO}$ electrolysis on solid Ni-N-C catalysts at industrial current densities. Energy Environ. Sci. 12, 640-647 (2019).

16. Han, Y. H. et al. Electronic structure engineering to boost oxygen reduction activity by controlling the coordination of the central metal. Energy Environ. Sci. 11, 2348-2352 (2018)

17. Kou, Z. K. et al. Molybdenum carbide-derived chlorine-doped ordered mesoporous carbon with few-layered graphene walls for energy storage applications. ACS Appl. Mater. Interfaces 9, 3702-3712 (2017).

18. Kabir, S., Artyushkova, K., Serov, A., Kiefer, B. \& Atanassov, P. Binding energy shifs for nitrogen-containing graphene-based electrocatalysts-experiments and DFT calculations. Surf. Interface Anal. 48, 293-300 (2016).

19. Lin, Y.-C. et al. Structural and chemical dynamics of pyridinic-nitrogen defects in graphene. Nano Lett. 15, 7408-7413 (2015).

20. Yang, H. B. et al. Atomically dispersed $\mathrm{Ni}(\mathrm{I})$ as the active site for electrochemical $\mathrm{CO}_{2}$ reduction. Nat. Energy 3, 140-147 (2018).

21. Avakyan, L. A. et al. Atomic structure of nickel phthalocyanine probed by Xray absorption spectroscopy and density functional simulations. Opt. Spectrosc. 114, 347-352 (2013).

22. Li, J. Z. et al. Atomically dispersed manganese catalysts for oxygen reduction in proton-exchange membrane fuel cells. Nat. Catal. 1, 935-945 (2018).

23. Yang, Y. et al. O-, N-Atoms-coordinated $\mathrm{Mn}$ cofactors within a graphene framework as bioinspired oxygen reduction reaction electrocatalysts. Adv. Mater. 30, 1801732 (2018).

24. Zhao, S. L. et al. Ultrathin metal-organic framework nanosheets for electrocatalytic oxygen evolution. Nat. Energy 1, 1-10 (2016).

25. Domenick, F. L. \& Timothy, A. Mn K-edge X-ray absorption studies of oxoand hydroxo-manganese(IV) complexes: experimental and theoretical insights into pre-edge properties. Inorg. Chem. 53, 6179-6194 (2014). Jackson.

26. Fei, H. L. et al. General synthesis and definitive structural identification of $\mathrm{MN}_{4} \mathrm{C}_{4}$ single-atom catalysts with tunable electrocatalytic activities. Nat. Catal. 1, 63-72 (2018).

27. $\mathrm{Li}, \mathrm{Q}$. H. et al. Fe Isolated single atoms on $\mathrm{S}, \mathrm{N}$ codoped carbon by copolymer pyrolysis strategy for highly efficient oxygen reduction reaction. Adv. Mater 30, 1800588 (2018).

28. Liu, W. et al. Single-site active cobalt-based photocatalyst with long carriers lifetime for spontaneous overall water splitting. Angew. Chem. Int. Ed. 56, 9312-9317 (2017)

29. Li, X. G. et al. Exclusive Ni-N4 sites realize near-unity CO selectivity for electrochemical $\mathrm{CO}_{2}$ reduction. J. Am. Chem. Soc. 139, 14889-14892 (2017).

30. Marken, F., Neudeck, A. \& Bond, A. M. Electroanalytical Methods: Guide to Experiments and Applications (ed. Scholz, F.) 57-106 (Springer, Berlin, 2010)

31. Yang, F. et al. Highly efficient $\mathrm{CO}_{2}$ electroreduction on $\mathrm{ZnN}_{4}$-based singleatom catalyst. Angew. Chem. Int. Ed. 57, 12303-12307 (2018).

32. Lin, S. et al. Covalent organic frameworks comprising cobalt porphyrins for catalytic $\mathrm{CO}_{2}$ reduction in water. Science 349, 1208-1213 (2015).

33. Zhang, $\mathrm{X}$. et al. Highly selective and active $\mathrm{CO}_{2}$ reduction electro-catalysts based on cobalt phthalocyanine/carbon nanotube hybrid structures. Nat. Commun. 8, 14675 (2017). 
34. Han, N. et al. Supported cobalt polyphthalocyanine for high-performance electrocatalytic $\mathrm{CO}_{2}$ reduction. Chem 3, 652-664 (2017).

35. Wang, X. Q. et al. Regulation of coordination number over single Co sites: triggering the efficient electroreduction of $\mathrm{CO}_{2}$. Angew. Chem. Int. Ed. 57, 1944-1948 (2018).

36. Pan, Y. et al. Design of single-atom Co- $\mathrm{N}_{5}$ catalytic site: a robust electrocatalyst for $\mathrm{CO}_{2}$ reduction with nearly $100 \% \mathrm{CO}$ selectivity and remarkable stability. J. Am. Chem. Soc. 140, 4218-4221 (2018).

37. Kramer, W. W. \& McCrory, C. C. L. Polymer coordination promotes selective $\mathrm{CO}_{2}$ reduction by cobalt phthalocyanine. Chem. Sci. 7, 2506-2515 (2016).

38. Zhao, C. M. et al. Ionic exchange of metal-organic frameworks to access single nickel sites for efficient electroreduction of $\mathrm{CO}_{2}$. J. Am. Chem. Soc. 139, 8078-8081 (2017).

39. Zhang, C. $\mathrm{H}$. et al. Electrochemical $\mathrm{CO}_{2}$ reduction with atomic iron-dispersed on nitrogen-doped graphene. Adv. Energy Mater. 8, 1703487 (2018).

40. Yang, J. et al. In-situ thermal atomization to transfer supported metal nanoparticles to surface enriched $\mathrm{Ni}$ single atom catalyst. Angew. Chem. Int. Ed. 57, 14095-14100 (2018).

41. Tornow, C. E., Thorson, M. R., Ma, S., Gewirth, A. A. \& Kenis, P. J. A. Nitrogen-based catalysts for the electrochemical reduction of $\mathrm{CO}_{2}$ to $\mathrm{CO}$. J. Am. Chem. Soc. 134, 19520-19523 (2012).

42. Xie, J. F. et al. Metal-free fluorine interlayer doped carbon electrocatalyst for $\mathrm{CO}_{2}$ reduction outcompeting hydrogen evolution. Angew. Chem. Int. Ed. 57, 9640-9644 (2018).

43. Ghausi, $\mathrm{M}$. A. et al. $\mathrm{CO}_{2}$ overall splitting by a bifunctional metal-free electrocatalyst. Angew. Chem. Int. Ed. 57, 13135-13139 (2018).

44. Menges, F. S. et al. Capture of $\mathrm{CO}_{2}$ by a cationic nickel(I) complex in the gas phase and characterization of the bound, activated $\mathrm{CO}_{2}$ molecule by cryogenic ion vibrational predissociation spectroscopy. Angew. Chem. Int. Ed. 55, 1282-1285 (2016).

45. Fujita, E., Furenlid, L. R. \& Renner, M. W. Direct XANES evidence for charge transfer in $\mathrm{Co}-\mathrm{CO}_{2}$ complexes. J. Am. Chem. Soc. 119, 4549-4550 (1997)

46. Sakaki, S. et al. Can carbon dioxide coordinate to a nickel(I) complex? An ab initio MO/SD-CI study. J. Am. Chem. Soc. 112, 7813-7814 (1990).

47. Oiu, H.-J. et al. Nanoporous graphene with single-atom nickel dopants: an efficient and stable catalyst for electrochemical hydrogen production. Angew. Chem. Int. Ed. 54, 14031-14035 (2015).

48. Duan, X. et al. Metal-free carbon materials for $\mathrm{CO}_{2}$ electrochemical reduction. Adv. Mater. 29, 1701784 (2017).

49. Jia, Q. et al. Experimental observation of redox-induced Fe-N switching behavior as a determinant role for oxygen reduction activity. ACS Nano $\mathbf{9}$, 12496-12505 (2015)

50. Zhou, Y. S. et al. Dopant-induced electron localization drives $\mathrm{CO}_{2}$ reduction to $C_{2}$ hydrocarbons. Nat. Chem. 10, 974-980 (2018).

\section{Acknowledgements}

The authors thank the financial supports from National Natural Science Foundation of China (21525316, 21673254), Ministry of Science and Technology of China (2017YFA0403003), Chinese Academy of Sciences (QYZDY-SSW-SLH013).

\section{Author contributions}

B.X.Z. performed the whole experiments. L.F.L., C.L., X.N.T., X.Y.C. and Z.Z.S. worked on material characterizations. J.B.S., D.X.T. and F.Y.Z. worked on elcetrocatalysis experiment. L.R.Z. and J.Z. worked on XAFS experiment. J.L.Z., B.X.Z., and B.X.H. analysed the data. J.L.Z. and B.X.Z. co-wrote the paper. J.L.Z. conceived the project.

\section{Additional information}

Supplementary Information accompanies this paper at https://doi.org/10.1038/s41467 019-10854-1.

Competing interests: The authors declare no competing interests.

Reprints and permission information is available online at http://npg.nature.com/ reprintsandpermissions/

Peer review information: Nature Communications thanks the anonymous reviewers for their contribution to the peer review of this work.

Publisher's note: Springer Nature remains neutral with regard to jurisdictional claims in published maps and institutional affiliations.

(c) (i) Open Access This article is licensed under a Creative Commons Attribution 4.0 International License, which permits use, sharing, adaptation, distribution and reproduction in any medium or format, as long as you give appropriate credit to the original author(s) and the source, provide a link to the Creative Commons license, and indicate if changes were made. The images or other third party material in this article are included in the article's Creative Commons license, unless indicated otherwise in a credit line to the material. If material is not included in the article's Creative Commons license and your intended use is not permitted by statutory regulation or exceeds the permitted use, you will need to obtain permission directly from the copyright holder. To view a copy of this license, visit http://creativecommons.org/ licenses/by/4.0/.

(C) The Author(s) 2019 